\title{
Nickel Plating on Steel by Chemical Reduction
}

\author{
By Abner Brenner and Grace E. Riddell
}

\begin{abstract}
A process has been developed for the production of adherent nickel deposits of good quality on steel without the use of an electric current. The deposition of nickel is brought about by chemical reduction of a nickel salt with hypophosphites in a hot ammoniacal solution. The reaction is catalytic and, under the prescribed conditions of concentration and $\mathrm{pH}$, no reduction occurs in the solution unless certain metals, such as steel or nickel, are introduced into the bath. The reduction then occurs only at the surface of the immersed metal with the production of a coating of nickel of 96 to 97 percent purity.
\end{abstract}

\section{Introduction}

In the course of an investigation on a nickel plating bath an unusual chemical reaction was accidentally encountered, by means of which nickel deposits of good quality can be produced on a steel or nickel surface without the use of an electric current. The reaction involves reduction by hypophosphites in a heated nickel solution. In the nickel bath being investigated, trouble was had with the oxidation of some constituents of the bath at an insoluble anode, and to obviate this difficulty typical reducing agents were added. In one of the experiments the surprising result of an apparent cathode current efficiency of 130 percent was obtained, although during the plating there was considerable gassing at the cathode, which usually indicates a low current efficiency.
Furthermore, the object being plated, which was a tube with an inside anode, was found to have been completely plated on the outside, although no external anodes had been used. Although this process will not replace electrodeposition of nickel, it may prove useful for special applications.

\section{Contents}

I. Introduction

II. Literature . . . . . . . . . . . . . . . . 32

III. General principles. . . . . . . . . . . 32

IV. Bath composition and operating condition . . . 33

V. Other methods of chemical reduction . . . . 34 


\section{Literature}

The foregoing experience with the hypophosphite reduction occurred before it was noted that this reaction had been previously reported. An investigation of the literature disclosed that the reduction of nickel solutions with hypophosphite to produce metallic nickel had been observed by Wurtz. ${ }^{1}$ The reaction was studied in detail by Bretau, ${ }^{2}$ Paal and Friederici, ${ }^{3}$ Scholder and Heckel, ${ }^{4}$ and Scholder and Haken. ${ }^{5}$ These workers used high concentrations of hypophosphite, usually several hundred grams per liter, to effect the reduction. The solution containing the nickel salt was heated on a steam bath for several hours, if necessary, until the reaction began. The reaction was usually quite vigorous, much hydrogen was evolved, and the mass bubbled up to 10 or 20 times its original volume. The nickel was obtained mainly as a dark powder, but occasionally it deposited on the walls of the flask as a mirror, which gradually became detached and broke up into thin flakes.

The reaction by which nickel is produced is

or

$$
\begin{aligned}
& \mathrm{NiCl}_{2}+\mathrm{NaH}_{2} \mathrm{PO}_{2}+\mathrm{H}_{2} \mathrm{O} \rightarrow \\
& \mathrm{Ni}+2 \mathrm{HCl}+\mathrm{NaH}_{2} \mathrm{PO}_{3}
\end{aligned}
$$

$$
\mathrm{Ni}^{++}+\mathrm{H}_{2} \mathrm{PO}_{2}^{-}+\mathrm{H}_{2} \mathrm{O} \rightarrow \mathrm{Ni}^{\circ}+2 \mathrm{H}^{+}+\mathrm{H}_{2} \mathrm{PO}_{3}^{-} \text {. }
$$

Concurrently, some of the hypophosphite is oxidized by the water, particularly in the presence of certain metals, to phosphite, and hydrogen is liberated:

$$
\mathrm{NaH}_{2} \mathrm{PO}_{2}+\mathrm{H}_{2} \mathrm{O} \rightarrow \mathrm{NaH}_{2} \mathrm{PO}_{3}+\mathrm{H}_{2} \text {. }
$$

These equations show that the reaction mixture becomes more acid, as either an acid salt or free acid is produced. The reduction of nickel ion (eq. 1) is catalyzed by certain metals, including nickel, and as nickel is produced by the reaction, it is therefore autocatalytic. This explains why the reaction, which is rather slow in starting, proceeds with so much vigor after it once begins.

Some of the above investigators obtained cobalt by a hypophosphite reduction similar to that used for nickel. Only alkaline solutions could be used, and the reduction was slower than that of nickel.

The product which these workers (see footnotes 3 and 4) obtained from an initially neutral nickel solution was not pure nickel but a mixture of phosphides, probably as $\mathrm{Ni}_{2} \mathrm{P}$ and $\mathrm{Ni}_{5} \mathrm{P}_{2}$ (see footnote 3 ), with perhaps some uncombined nickel. The precipitate usually contained 85 percent of nickel and about 12 percent of phosphorus, with small amounts of moisture and oxygen. The product obtained from an alkaline solution was much purer. It contained about 97 percent of nickel and 3 percent of phosphorus, and hence consisted largely of uncombined nickel. The nickel phosphides obtained by the hypophosphite reduction are more similar to an intermetallic compound, in which the phosphorus behaves as a metal, than to a phosphine derivative. They are soluble in acids only with difficulty and do not give off phosphine when so treated.

\section{General Principles}

In an extension of the work of the previous investigators, it was found that the reduction of nickel compounds to nickel could be so controlled as to cause the catalytic reduction to occur, with the virtual exclusion of the purely chemical reduction. Thus an adherent compact nickel coating could be deposited on certain metal surfaces immersed in the bath without any appreciable precipitation of nickel occurring throughout the bulk of the solution or on the walls of the glass vessel. This preferential deposition was made possible by employing dilute solutions of hypo-

\footnotetext{
1 Compt. rend. 21, 149 (1845)。

2 Bul. soc. chim. [4] 9, 518 (1911).

3 Ber. deut, chem. Geo. 64, 1766 (1931).

- Z. anorg. allgem. Chem.198, 329 (1931).

- Ber. deut. chem. Ges. 64, 2870 (1931).
}

phosphite, about 10 grams per liter instead of several hundred grams per liter. Under these conditions, the deposition of nickel occurs on the surface of iron, nickel, gold, cobalt, palladium, and aluminum, but not on platinum, copper, zinc, or lead.

The method differs from the common methods of chemically depositing metallic coatings from aqueous solutions. The formation of coatings by chemical replacement, such as the formation of a copper film on steel dipped in copper sulfate, involves solution of the base metal. Theformation of metallic films, such as silver, copper, or gold by reduction, does not necessarily involve any catalytic action, as the metal precipitates indiscriminately over all articles immersed in it, as well as on the walls of the vessel. 


\section{Bath Composition and Operating Conditions}

The composition of the baths may vary within wide limits. Some typical formulas are shown in table 1. The baths are operated at or above $90^{\circ} \mathrm{C}$ $\left(194^{\circ} \mathrm{F}\right)$. As already noted, they produce a deposit only on certain metals. In the absence of metals that catalyze nickel deposition, the baths are fairly stable. A bath containing hypophosphite has been kept at $90^{\circ} \mathrm{C}$ for 5 hours without deteriorating very much. At room temperature, a bath is stable for several days.

The nickel deposits contained about 97 percent of nickel, and therefore are similar to those that Paal and Friederici obtained from an alkaline solution.

TABLE 1.-Bath compositions

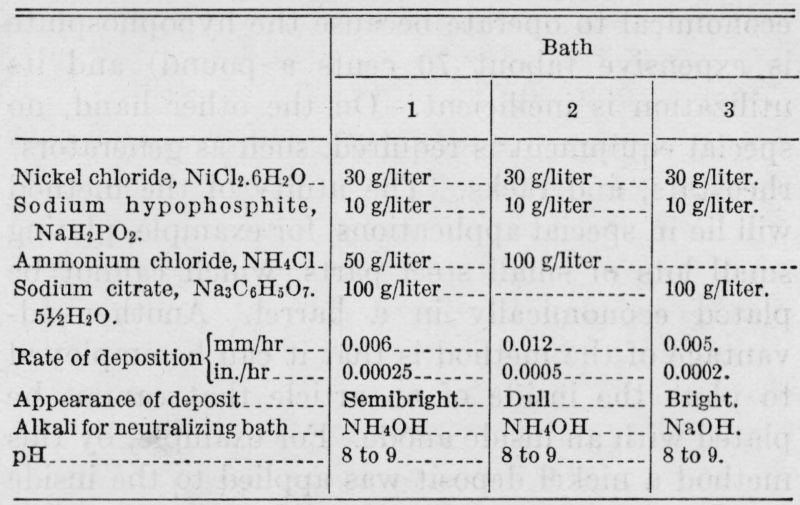

Steel objects to be plated are cleaned by any of the accepted procedures and are given an acid dip before being placed in the bath. The parts to be plated are suspended in the bath, for example, by a string. Small objects may be held on cloth stretched over a frame and should be agitated occasionally, although there is no need of constant motion, as in barrel plating, because current distribution is not involved. During the deposition a considerable amount of hydrogen is evolved from the surface of the metal. Under the conditions of operation outlined, nickel deposits only on the steel. However, after a bath has operated in a glass vessel for about 5 hours, a small amount of a precipitate containing nickel may deposit on the bottom of the vessel where the source of heat has been applied. If this precipitate is not removed, it may cause decomposition of some of the hypophosphite, just as another metal surface does.

The thickness of nickel deposited in a given time depends in part on the relation of the steel surface to the volume of the bath. The values in the above table were obtained with an area of 1 square decimeter (16 square inches) in 1 liter (1.1 quart) of solution. The rate of plating is less than that usually employed in nickel electroplating in a tank, but is about the same as in barrel plating. Because of the gradual exhaustion of the hypophosphite, less nickel will deposit during each succeeding interval of time. Most of the nickel is deposited during the first hour, and the reaction is virtually complete in 2 hours, unless more hypophosphite is added.

As the hypophosphite is gradually exhausted, more must be added if thick deposits are required, especially if the area to be plated is relatively large compared to the volume of solution. Additions of 5 grams of hypophosphite per liter may be made at half-hour or 1-hour intervals. Thereby, deposits 0.002 inch $(0.05 \mathrm{~mm})$ thick have been obtained in about 6 hours. As pointed out in equations 1 and 2, the hypophosphite becomes converted into phosphite, which, however, does not interfere with the operation of the bath. When the bath becomes too concentrated with this compound, it would be more economical to discard the bath than to try to remove the phosphite.

When the bath becomes depleted in nickel, additional nickel must be added in the form of soluble nickel salts. The function of the ammonium salts or the citrates is to keep nickel in solution at a $\mathrm{pH}$ of 8 to 9 . Ammonia has the disadvantage of being volatile at the temperature at which the bath is operated, but it is more satisfactory than organic amines, which were tried as substitutes. The citrate can be replaced by other hydroxy-organic acids, such as tartaric, without affecting the operation of the bath. Bath 1 (see table 1) is the preferred composition. Bath 2 , which does not contain any citrate, plates more rapidly than bath 1 , but the deposits are dull and more likely to be rough, and the bath does not remain as clear during operation. Bath 3 , with no ammonium salts, gave the brightest deposits, but had the disadvantage that after the deposits had reached a thickness of about 0.0002 inch, they ceased to become thicker even after several hours.

The reason for using a low concentration of hypophosphite, as already pointed out, is to obtain a deposition on the articles without producing 
"nickel black" throughout the bath. A similar consideration governs the chosen concentration of ammonium salts, too high a concentration of which will cause the chemical reduction to take place with liberation of nickel on the walls of the vessel. A higher nickel concentration tends to produce rough deposits.

The temperature of operation of the bath is important. At temperatures below $90^{\circ} \mathrm{C}$. the rate of deposition of nickel is slower, and the deposit is more likely to contain impurities. For example, at $60^{\circ} \mathrm{C}$. the rate of deposition is about half that at $90^{\circ} \mathrm{C}$. Nickel may be slowly deposited on steel at room temperature from a bath that has a high concentration of hypophosphite.

The $\mathrm{pH}$ of the bath should be kept between 8 and 9 to obtain the best deposits. On operation of the bath the $\mathrm{pH}$ drops because of the formation of hydrogen ions, as shown in equations 1 and 2 . Also, the volatilization of the ammonia causes a drop in the $\mathrm{pH}$. The $\mathrm{pH}$ is readily kept at the required value by adding ammonia water occasionally, so as to keep the bath perceptibly ammoniacal in odor.

The efficiency of the reduction of nickel salts to nickel is not very high because, as pointed out in connection with reaction 2 , some of the hypophosphite is catalytically oxidized by water with the liberation of hydrogen. The best yield of nickel that has been obtained was about 37 percent, based on the conversion of the hypophosphite to phosphite. This yield, obtained with a large area of metal in the bath, amounts to a reduction of about 2 grams of nickel by 10 grams of hypophosphite. With a small area of metal in the bath, the efficiency of deposition is likely to be about 20 percent.

The adhesion of the nickel deposit to mild steel is such that it cannot be flaked off by bending. However, the adhesion is less satisfactory on highcarbon steel.

Salt-spray tests were made on steel coated with $0.0002,0.0005$, and 0.001 inch of this reduced nickel, in comparison with similar panels coated with electrodeposited nickel. The protective value of the two types of nickel was virtually the same.

The chemical method of plating nickel is not economical to operate because the hypophosphite is expensive (about 70 cents a pound) and its utilization is inefficient. On the other hand, no special equipment is required, such as generators, rheostats, and racks. The utility of the method will lie in special applications, for example, plating small lots of small steel parts, which cannot be plated economically in a barrel. Another advantage of the method is that it can be employed to plate the inside of an article that cannot be plated with an inside anode. For example, by this method a nickel deposit was applied to the inside of a bent steel tube one-fourth inch in diameter.

\section{Other Methods of Chemical Reduction}

The reduction of nickel and cobalt salts to the metal is a rather rare chemical phenomenon, of which we have found no recorded examples other than the method employing hypophosphites. In the course of some other work another system was encountered in which nickel and cobalt salts can be reduced to metal, but the reduction is not as simple or practicable as the hypophosphite method. This reaction involves the reduction of nickel or cobalt in an alkaline solution with lower valent molybdenum compounds. The molybdenum, in the form of molybdate in a strongly acid solution, is electrolytically reduced in a porous cell, preferably with a lead cathode, to the reddish- brown solution of the lower valent salt. When this solution is added to an alkaline metal solution containing hydroxyacetates (to keep molybdenum and cobalt compounds from precipitating), a thin mirror of nickel or cobalt will form on the walls of the test tube and some gas will be liberated.

Cobalt deposits have been obtained by another reaction, which was not conducted in aqueous solution. A cobalt salt was dissolved in molten potassium formate or hydroxyacetate or a mixture of the two, which melts at about $150^{\circ} \mathrm{C}$. When a rod of copper or gold was left in the melt for some hours, a thin, bright coating of cobalt was obtained as a result of chemical reduction.

Washington, April 11, 1946. 